Pediat. Res. 2: 254-263 (1968)

Glycine

hydroxymethyl-

tetrahydrofolate hyperglycinemia, nonketotic

\title{
Metabolism of Glycine in the Nonketotic Form of Hyperglycinemia
}

\author{
T. Ando, W. L. Nyhan ${ }^{[31]}$, T. Gerritsen, L. Gong, D. G. Heiner and P.F.Bray \\ Departments of Pediatrics, University of Miami School of Medicine, Miami, Florida, \\ University of Wisconsin Medical School, Madison, Wisconsin, and \\ University of Utah College of Medicine, Salt Lake City, Utah, USA
}

\section{Extract}

Hyperglycinemia is a disorder of amino acid metabolism characterized by the presence of increased concentrations of glycine in the blood, urine, and cerebrospinal fluid. It is now recognized that there are two forms of hyperglycinemia each representing distinct diseases. These studies were designed to assess the metabolism of glycine in the nonketotic form of hyperglycinemia. Isotope content was assessed in respiratory $\mathrm{CO}_{2}$ and in glycine, serine and the $\beta$ carbon of serine of plasma after the separate intravenous injections of glycine- $1-{ }^{14} \mathrm{C}$ and glycine-2-14 $\mathrm{C}$.

The specific activities of ${ }^{14} \mathrm{CO}_{2}$ isolated from expired air after the injection of glycine-1 ${ }^{14} \mathrm{C}$ (fig. 2) declined in control subjects from peak values at 10 to 15 minutes in nearly linear fashion over a 2-hour period. In contrast, curves obtained in the patients were rather flat, rising slowly after injection to highest values at about 60 minutes. At 15 minutes, values for the control individuals exceeded those of the patients by a factor of 5- to 10-fold. These data indicate a defect in the formation of ${ }^{14} \mathrm{CO}_{2}$ from the first carbon of glycine. When the control subjects were infused with nonisotopic glycine to produce pools comparable to those found in the patient, the specific activities of the serine isolated from plasma after the injection of glycine- $1{ }^{14} \mathrm{C}$ (table II) were virtually the same in both groups. The rate of conversion of glycine-2- ${ }^{14} \mathrm{C}$ to serine (fig. 3 ) in the patients was, however, considerably slower than it was in the control subjects for at least the first 30 minutes, and the curves were flat throughout. Degradation of the serine isolated from plasma and precipitation of the $\beta$ carbon as formaldemethone indicated that the incorporation of the $\alpha$ carbon of glycine into the $\beta$ carbon of serine was much higher in the controls than in the patients (fig.4). The curves for the patients approximated the abscissa indicating virtually no conversion.

These data indicate that in nonketotic hyperglycinemia there is a defect in the oxidation of carbon 1 of glycine to $\mathrm{CO}_{2}$ and in the conversion of carbon 2 of glycine to carbon 3 of serine. This is consistent with a defect in an enzyme catalyzing the transformation of glycine to $\mathrm{CO}_{2}, \mathrm{NH}_{3}$ and hydroxymethyltetrahydrofolate.

\section{Speculation}

The data obtained indicate that patients with nonketotic hyperglycinemia are unable in vivo to convert the first carbon of glycine directly to $\mathrm{CO}_{2}$ and the second carbon of glycine to the third carbon of serine. This is consistent with a genetic defect in an enzyme which catalyzes decarboxylation and formation of hydroxymethyltetrahydrofolate from glycine. It should be possible to document such a defect at a cellular and subcellular level. 


\section{Introduction}

Hyperglycinemia is a disorder of amino acid metabolism in which glycine concentrations in the blood, urine and cerebrospinal fluid are increased. It is now recognized that there are two distinct forms of hyperglycinemia. Ketotic hyperglycinemia is characterized by the presence of mental retardation, neutropenia, and recurrent episodes of ketoacidosis progressing to coma [6]. Hyperglycinemia and ketosis may also be features of methylmalonic aciduria [23]. GERRITSEN et al. [9] described a hyperglycinemic patient who lacked manifestations of ketotic hyperglycinemia, but had mental retardation, convulsions, spastic cerebral palsy and a diminished excretion of oxalic acid in the urine. Nonketotic hyperglycinemia has recently been observed in a second patient [5]. Two siblings reported by MABRY and KARAM [15] may represent the same syndrome. PRADER et al. [20] have studied a patient with hyperglycinemia who was nonketotic and nonhypooxaluric, suggesting that hypooxaluria may not be an integral feature of the syndrome.

The studies reported here were designed to assess the metabolism of glycine in nonketotic hyperglycinemia. A schematic representation of glycine metabolism

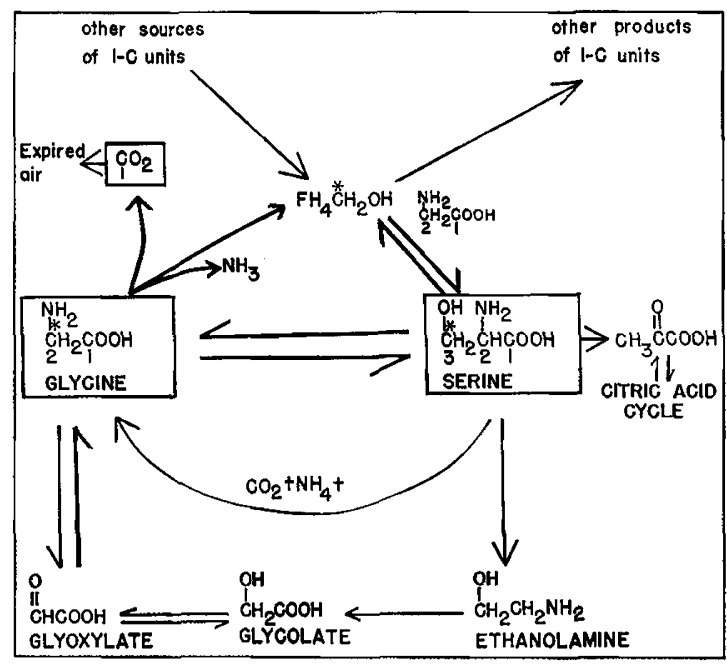

Fig. 1. Metabolism of glycine and the interconversions of glycine and serine. The carbon atoms of glycine and serine are numbered, and an asterisk is employed to illustrate the conversion of the second carbon of glycine to the third carbon of serine via a folic acid intermediate. Abbreviations include $\mathrm{FH}_{4}$ for tetrahydrofolic acid and 1-C-unit for single carbon unit. The other sources of the 1-G-unit include some products of glycine metabolism including that of the Shemin succinyl CoAglycine cycle and formate which is formed from glyoxylate. is given in figure 1. Separate experiments were carried out using glycine-1 $1{ }^{14} \mathrm{C}$ and glycine-2- ${ }^{14} \mathrm{C}$ in two patients and in three control individuals. The isotope content was determined in respiratory $\mathrm{CO}_{2}$ and in glycine and serine isolated from the plasma. The serine isolated was degraded in order to quantitate the formation of the $\beta$-carbon (carbon 3) from glycine. A defect was found in the metabolism of glycine. This was consistent with an abnormality in the conversion of glycine to $\mathrm{CO}_{2}$ and hydroxymethyltetrahydrofolate.

\section{Subjects \\ Materials and Methods}

Two patients with nonketotic hyperglycinemia were studied. The first patient, T.Z., reported by ZITER et al. [5], was 2 years old and weighed $11.3 \mathrm{~kg}$ at the time of study. S.F., the subject of the initial report of nonketotic hyperglycinemia by GerRITSEN et al. [9] was 6 years, 9 months of age, and weighed $16.1 \mathrm{~kg}$ when the experiment was performed.

Control subjects were about the same size as the patients and represented individuals of similar developmental maturation. They were screened from a biochemical point of view and had no demonstrable metabolic abnormalities. J.E. was a 7-year, 4-month-old boy weighing $15 \mathrm{~kg}$, with the Cornelia de Lange syndrome. M.S. was a 4-year-old boy weighing $13.0 \mathrm{~kg}$, with an absence of sensation of pain and developmental retardation. M.K. was a $51 / 2$-year-old boy, weighing $16.0 \mathrm{~kg}$, with Lowe's syndrome; his renal tubular defect was presumably unrelated to glycine metabolism [30].

\section{Isotopic Glycine}

Glycine-1 $1{ }^{14} \mathrm{C}$ was obtained from the New England Nuclear Corp. and had a specific activity of $6.34 \mathrm{mc} /$ $\mathrm{mM}$. Glycine-2-14 $\mathrm{C}$ was obtained from the NuclearChicago Corp. and had a specific activity of $21.5 \mathrm{mc} /$ $\mathrm{mM}$. Radiochemical purity and stability of the label in glycine were repeatedly assessed by column chromatography and liquid scintillation counting. Samples for injection were made isotonic with saline and sterilized by autoclaving.

\section{Procedures}

Following an overnight fast, each subject was given $2.0 \mu \mathrm{c} / \mathrm{kg}$ of glycine-1-14 $\mathrm{C}$ by intravenous injection. Glycine-2-214 $\mathrm{C}$ was injected intravenously at least 4 days after the injection of glycine-1 $14 \mathrm{C}$.

In two of the control individuals, J.E. and M.K., the experiment was carried out in a manner similar to that used in the patients. In two additional experiments with control subjects (J.E. and M.S.), the conditions were changed. The glycine pools were increased to 
levels comparable to those found in the patients. This was done by the infusion of nonlabeled glycine [27], at a rate of $60 \mathrm{mg} / \mathrm{kg} / \mathrm{h}$ for 60 minutes prior to the injection of the isotope and for 60 minutes thereafter.

Expired air was collected at intervals over the first 24 hours following the injection of the labeled compound with a Scott inhalator mask adjusted to the patient's face. The mask was connected to two oneway $\mathrm{J}$ valves which allowed for inspiration of room air. Expired gases passed into a 13-liter rubber breathing bag. Periods of collection were of 3 to 10 minutes in duration; collections were relatively frequent during the first one to two hours. Heparinized venous blood was obtained at intervals over the first hour after injection and placed immediately in ice. The plasma was then removed and stored frozen to await analysis.

\section{Analytical Methods}

$\mathrm{CO}_{2}$ was absorbed from the bags of expired air in a mixture of ethanolamine:methylcellosolve $1: 2$ [10] using a modification of the procedure described by FREDRICKSON and ONo [7]. Each bag was connected to a flow system which proceeded first through a $70 \mathrm{ml}$ side-arm test tube in an acetone dry ice mixture, in order to trap water, and then through a series of $30 \mathrm{ml}$ screw cap test tubes placed inside $70 \mathrm{ml}$ side-arm test tubes. The first tube contained $15 \mathrm{ml}$ and the second and third tubes, $7.5 \mathrm{ml}$ of the trapping mixture. In each instance, air entered the trapping mixture through a drawn-out disposable Pasteur pipette placed in the stopper of the larger tube and exited via the side arm into the next tube. A Model 2590 B Wappler-Stedman suction pump was used to move air through the system. After a bag was emptied, the inner test tubes were removed and their screw caps applied tightly to await assay of the contents. The amount of absorbed ${ }^{14} \mathrm{CO}_{2}$ was determined by counting $3.0 \mathrm{ml}$ from each tube in a mixture of toluene, methylcellosolve and 2,5-diphenyloxazole (PPO) [10] using a liquid scintillation spectrometer. The $\mathrm{CO}_{2}$ content of the absorbed ${ }^{14} \mathrm{CO}_{2}$ was determined by the method of VAN SLYKE [25] using concentrated lactic acid and a $0.2 \mathrm{ml}$ aliquot of trapping solution. Specific activities in dpm per $\mathrm{mM}$ were calculated from these two values.

Plasma samples were deproteinized with $4 \%$ sulfosalicylic acid and the amino acids separated by chromatography on columns of the Beckman-Spinco Automatic Amino Acid Analyzer [26]. The eluant was collected directly from the bottom of the column in fractions of $2.2 \mathrm{ml}$ in a fraction collector. Aliquots of 0.5 and $1.0 \mathrm{ml}$ were removed and assayed for amino acid content using the ninhydrin reaction [17] and for radioactivity in a liquid scintillation spectrometer. Counting was"carried out in $15 \mathrm{ml}$ of Bray's dioxane mixture [4] with $0.5 \mathrm{ml}$ of $0.12 \mathrm{~N} \mathrm{HCl} \mathrm{[19].}$
Serine was degraded with periodate in order to assess the labeling of $\beta$-carbon. Aliquots of 0.5 or $1.0 \mathrm{ml}$ of each of the fractions containing serine were pooled in a flask and oxidized using $\mathrm{NaIO}_{4}$ [8]. The formaldehyde formed was passed through a Dowex-1-chlo. ride column [12]. Dimedon solution was then added to yield crystals of formaldemethone [16]. The crystals were washed several times with water and recrystallized from hot ethanol. The crystals were dissolved directly in an aliquot of the scintillation mixture $(5.0 \mathrm{~g}$ PPO, $0.1 \mathrm{~g}$ 1,4-bis-[2-5-phenyloxazolyl]-benzene [POPOP] and toluene to 1 liter), and transferred to a counting vial. The container was washed 3 times with the scintillation mixture, the solutions combined and brought to a total volume of $15 \mathrm{ml}$. Counting was carried out in a liquid scintillation spectrometer. The radioactivity of formaldemethone was corrected for the rates of recovery determined using known amounts of serine-3${ }^{14} \mathrm{C}$ subjected to the entire procedure. Recovery was found to be $85-92 \%$.

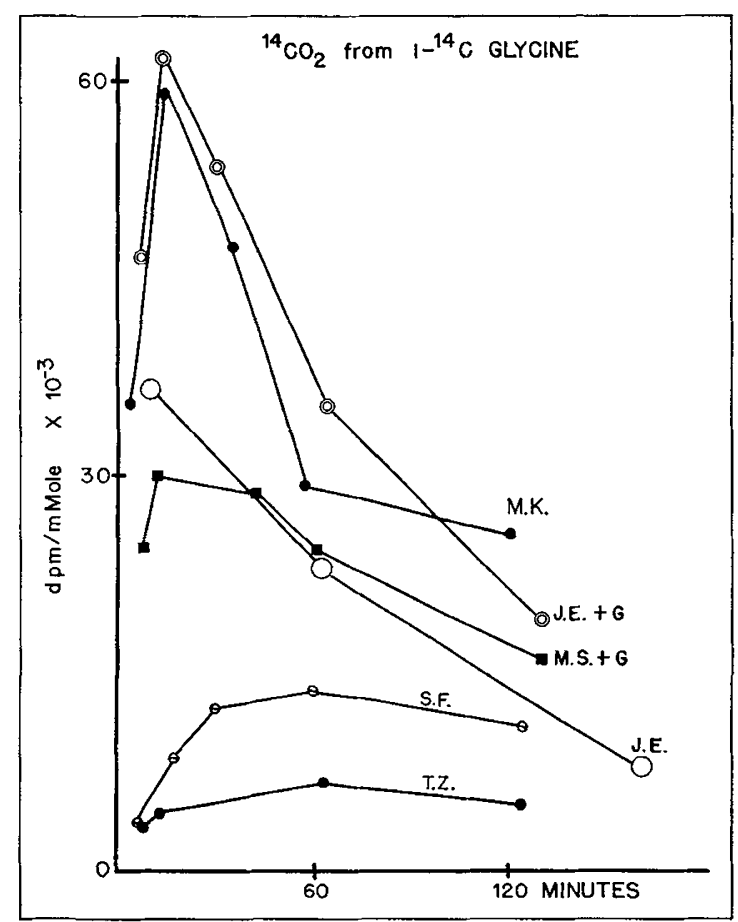

Fig. 2. Formation of ${ }^{14} \mathrm{CO}_{2}$ from glycine-1-14 $\mathrm{C}$ in two patients and three control individuals. The designation $+G$ in this and in subsequent figures indicates the formation of an increased glycine pool by the intravenous infusion of unlabeled glycine. T.Z. and S.F. were patients with hyperglycinemia and J.E., M.S. and M.K. were control individuals. 
Table $I .{ }^{14} \mathrm{CO}_{2}$ in the expired air

\begin{tabular}{|c|c|c|c|c|}
\hline \multirow{2}{*}{$\frac{\text { Labelled substrate }}{\text { Control subjects }}$} & \multicolumn{2}{|c|}{ Glycine-1-14 $\mathrm{C}$} & \multicolumn{2}{|c|}{ Glycine-2-14 $\mathrm{C}$} \\
\hline & $\begin{array}{l}\text { Time } \\
(\min )\end{array}$ & $\begin{array}{l}\text { Specific activity } \\
(\mathrm{dpm} / \mathrm{mM})\end{array}$ & $\begin{array}{l}\text { Time } \\
(\min )\end{array}$ & $\begin{array}{l}\text { Specific activity } \\
(\mathrm{dpm} / \mathrm{mM})\end{array}$ \\
\hline J.E. & $\begin{array}{r}10 \\
62 \\
163 \\
1446\end{array}$ & $\begin{array}{r}36,610 \\
22,630 \\
7,900 \\
630\end{array}$ & $\begin{array}{r}7 \\
12 \\
65 \\
124 \\
1443\end{array}$ & $\begin{array}{r}660 \\
1,210 \\
5,690 \\
5,030 \\
350\end{array}$ \\
\hline J.E.+glycine load & $\begin{array}{r}8 \\
15 \\
31 \\
65 \\
129\end{array}$ & $\begin{array}{l}46,670 \\
61,880 \\
53,600 \\
35,180 \\
19,220\end{array}$ & $\begin{array}{r}10 \\
18 \\
37 \\
66 \\
141\end{array}$ & $\begin{array}{r}3,890 \\
7,370 \\
12,010 \\
15,960 \\
13,890\end{array}$ \\
\hline M.S. + glycine load & $\begin{array}{r}5 \\
12 \\
42 \\
61 \\
129\end{array}$ & $\begin{array}{l}24,580 \\
30,060 \\
28,530 \\
24,500 \\
15,870\end{array}$ & & \\
\hline M.K. & $\begin{array}{r}3 \\
14 \\
35 \\
57 \\
120 \\
240 \\
1440\end{array}$ & $\begin{array}{r}35,770 \\
58,260 \\
47,710 \\
29,120 \\
25,100 \\
11,070 \\
2,210\end{array}$ & $\begin{array}{r}5 \\
17 \\
29 \\
60 \\
120 \\
240 \\
1440\end{array}$ & $\begin{array}{r}3,210 \\
3,080 \\
4,140 \\
13,730 \\
15,030 \\
7,480 \\
1,370\end{array}$ \\
\hline Patients T.Z. & $\begin{array}{r}8 \\
13 \\
63 \\
123 \\
1443\end{array}$ & $\begin{array}{r}3,040 \\
4,150 \\
6,490 \\
4,990 \\
410\end{array}$ & $\begin{array}{r}13 \\
63 \\
123 \\
1443\end{array}$ & $\begin{array}{r}690 \\
3,030 \\
5,370 \\
90\end{array}$ \\
\hline S.F. & $\begin{array}{r}7 \\
17 \\
30 \\
62 \\
122 \\
1442\end{array}$ & $\begin{array}{r}3,690 \\
8,950 \\
12,830 \\
13,790 \\
11,370 \\
1,310\end{array}$ & $\begin{array}{r}5 \\
14 \\
34 \\
67 \\
122 \\
1442\end{array}$ & $\begin{array}{l}1,750 \\
2,510 \\
4,820 \\
6,620 \\
8,210 \\
2,070\end{array}$ \\
\hline
\end{tabular}

\section{Results}

Oxidation of Glycine to $\mathrm{CO}_{2}$

Data on the conversion of glycine- $1{ }^{14} \mathrm{C}$ to ${ }^{14} \mathrm{CO}_{2}$ is illustrated in figure 2. In the controls, the specific activities of the ${ }^{14} \mathrm{CO}_{2}$ isolated from expired air declined in a nearly linear fashion for over $\mathbf{2}$ hours from peak values at 10 to 15 minutes. In contrast, the curves obtained in the patients were rather flat, rising slowly to highest values 60 minutes after injection. There was clear distinction between the data for patients and controls for 2 hours. At 15 minutes, values for the con- trols exceeded those of the patients by a factor of 5- to 10 -fold. These data indicate a defect in the formation of ${ }^{14} \mathrm{CO}_{2}$ from the first carbon of glycine.

That these findings are not a function of dilution of injected glycine in an abnormally large pool of unlabeled glycine is indicated by experiments in which nonisotopic glycine was infused to produce glycine concentrations in plasma of controls, similar to those found in patients. Though plasma concentration cannot be equated to pool size, a steady state for glycine concentration was obtained and body water was presumably constant. This is consistent with enlargement 
of the pool to a steady state in which infusion rate equals glycine turnover. The curves obtained in M.S. and J.E. were similar to those observed without glycine infusion. Furthermore, in J.E., who was studied in the presence and absence of infused nonisotopic glycine, the specific activities of $\mathrm{CO}_{2}$ were much higher in the presence of the glycine load. These data suggest that large amounts of glycine increase rather than decrease the conversion of the first carbon of glycine to $\mathrm{CO}_{2}$.

In the control subjects, the conversion of glycine-2${ }^{14} \mathrm{C}_{\text {to }}{ }^{14} \mathrm{CO}_{2}$ (table I) was much slower than was that of glycine- $1-{ }^{14} \mathrm{C}$. The curves obtained with glycine- $2-{ }^{14} \mathrm{C}$ in the controls were similar to those obtained in patients with glycine-1 $-{ }^{14} \mathrm{C}$, with maximal values generally at about 60 minutes. In the patients, the formation of ${ }^{14} \mathrm{CO}_{2}$ from glycine-2- ${ }^{14} \mathrm{C}$ was even slower than it was in the controls; peak levels were obtained at 2 hours. The quantitative differences between patients and controls, however, were not striking. In J.E., the specific activities of respiratory ${ }^{14} \mathrm{CO}_{2}$ were greater in the presence of an exogenous glycine load.

Conversion of Glycine to Serine

The specific activities of the serine isolated from plasma after the injection of glycine- $1-{ }^{14} \mathrm{C}$ are shown in table II. In the control subjects, in the absence of a glycine-infused state, the specific activities of serine decreased sharply from maxima at the earliest times studied. This observation indicated very rapid formation of serine from glycine. When the patients were compared directly with the controls, the specific activities of serine were lower and the curves in the patients were flatter. It is also evident from table II, however, that the specific activities of glycine in the patients were about half that found in the controls. Nonisotopic glycine was infused in the control subjects, J.E. and M.S., and plasma concentrations similar to those of the hyperglycinemic patient T.Z. were obtained. The specific activities of glycine and serine under these conditions were virtually the same in T.Z. and in the control subjects, and the shapes of the curves of specific activity of serine were similarly flat. These data suggest that the differences between controls and patients in the formation of serine from glycine $-1{ }^{14} \mathrm{C}$ are a function of dilution in pools of different size. The hyperglycinemic patient S.F. was studied at a later time. The concentrations of glycine in his plasma were somewhat higher than that of patient T.Z., and the specific activities of glycine and serine concomitantly were lower.

Table II. Isotope content in plasma of glycine and serine after the injection of glycine-1-14 $\mathrm{C}$

\begin{tabular}{|c|c|c|c|c|c|c|c|}
\hline \multirow[t]{2}{*}{ Control subjects } & \multirow{2}{*}{$\begin{array}{l}\text { Time } \\
\text { (min) }\end{array}$} & \multicolumn{3}{|c|}{ Serine } & \multicolumn{3}{|c|}{ Glycine } \\
\hline & & $\mu \mathrm{M} / 1$ & $\mathrm{dpm} / \mu \mathrm{M}$ & $\begin{array}{l}\text { plasma } \\
\mathrm{dpm} / \mathrm{ml}\end{array}$ & $\mu \mathrm{M} / 1$ & $\mathrm{dpm} / \mu \mathrm{M}$ & $\begin{array}{l}\text { plasma } \\
\mathrm{dpm} / \mathrm{ml}\end{array}$ \\
\hline \multirow[t]{4}{*}{ J.E. } & 5 & 121 & 4,820 & 561 & & & \\
\hline & 15 & 119 & 4,440 & 516 & 150 & 22,760 & 3,410 \\
\hline & 30 & 116 & 2,770 & 322 & & & \\
\hline & 60 & 116 & 1,160 & 135 & 150 & 2,740 & 410 \\
\hline \multirow[t]{3}{*}{ M.K. } & 10 & 134 & 3,390 & 454 & 214 & 26,400 & 5,650 \\
\hline & 29 & 119 & 3,080 & 367 & 185 & 9,550 & 1,770 \\
\hline & 62 & 102 & 653 & 41 & 171 & 1,100 & 189 \\
\hline \multirow[t]{4}{*}{ J.E. + glycine } & 7 & 104 & 2,680 & 278 & 756 & 10,360 & 7,840 \\
\hline & 15 & 108 & 2,030 & 220 & 834 & 4,920 & 4,100 \\
\hline & 29 & 100 & 2,170 & 217 & 762 & 2,610 & 1,990 \\
\hline & 58 & 134 & 710 & 95 & 566 & 1,350 & 764 \\
\hline \multirow[t]{4}{*}{ M.S. + glycine } & 6 & 119 & 2,770 & 328 & 568 & 14,540 & 8,260 \\
\hline & 16 & 112 & 2,760 & 309 & 526 & 6,550 & 3,450 \\
\hline & 37 & 99 & 2,460 & 243 & 461 & 3,290 & 1,150 \\
\hline & 57 & 124 & 1,190 & 147 & 588 & 1,650 & 970 \\
\hline \multirow[t]{7}{*}{ Patients T.Z. } & 7 & 92 & 2,400 & 225 & 626 & 13,540 & 8,810 \\
\hline & 17 & 94 & 2,580 & 242 & 655 & 6,660 & 4,360 \\
\hline & 31 & 94 & 2,440 & 229 & 670 & 5,080 & 3,330 \\
\hline & 60 & 95 & 2,110 & 198 & 669 & 2,930 & 1,920 \\
\hline & 10 & 114 & 1,450 & 166 & 956 & 6,750 & 6,450 \\
\hline & 21 & 160 & 970 & 155 & 871 & 4,470 & 3,890 \\
\hline & 37 & 155 & 770 & 119 & 932 & 2,950 & 2,750 \\
\hline
\end{tabular}


Data on the conversion of glycine- $2-{ }^{14} \mathrm{C}$ to serine are illustrated in figure 3 . In these experiments, the specific activities of serine in patients T.Z. and S.F. were considerably lower than those of controls for at least 30 minutes and the curves were flat throughout. Elevation of the size of the glycine pool in control subjects M.S. and J.E. did not yield curves that were similar to that of the patients. In fact, the highest specific activities obtained were those of M.S. under conditions of glycine infusion. Comparison of the specific activities of the glycine of the plasma (table III), as well as the concentrations of glycine, indicated that infusion of glycine produced greater dilution of the labeled glycine than had occurred in the experiments using glycine-1 -14C. Plasma levels were now comparable to those of the hyperglycinemic patients. These data are in accord with the concept that different processes are involved in the conversion of the first and second carbons of glycine to serine.

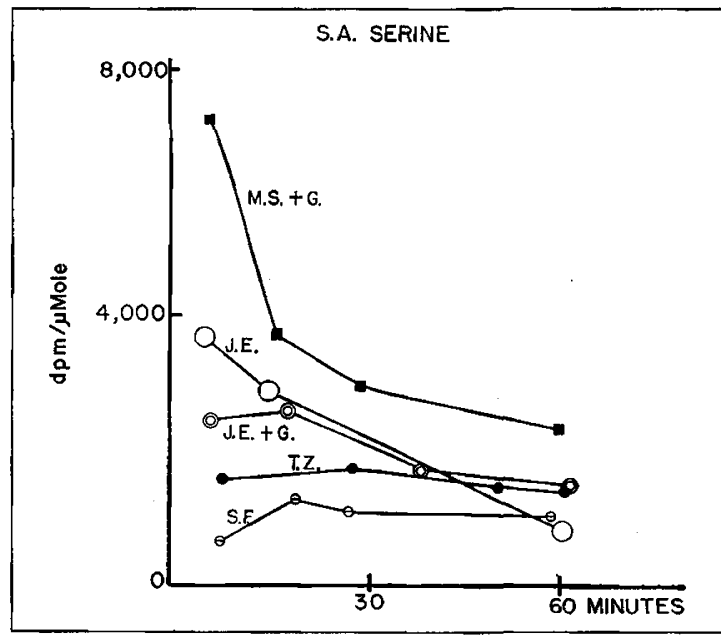

Fig. 3. Conversion of glycine-2-14 $\mathrm{C}$ to serine.

Table III. Isotope content in plasma of glycine and serine and of derived formaldemethone after injection of glycine-2-14 $\mathrm{C}$

\begin{tabular}{|c|c|c|c|c|c|c|c|c|}
\hline \multirow[t]{2}{*}{ Control subjects } & \multirow{2}{*}{$\begin{array}{l}\text { Time } \\
(\mathrm{min})\end{array}$} & \multirow{2}{*}{$\begin{array}{l}\text { FAM }^{\mathbf{1}} \\
\text { serine } \\
\mathrm{dpm} / \mu \mathrm{M}\end{array}$} & \multicolumn{3}{|c|}{ Serine } & \multicolumn{3}{|c|}{ Glycine } \\
\hline & & & $\mu \mathrm{M} / 1$ & $\mathrm{dpm} / \mu \mathrm{M}$ & $\begin{array}{l}\text { plasma } \\
\mathrm{dpm} / \mathrm{ml}\end{array}$ & $\mu \mathrm{M} / 1$ & $\mathrm{dpm} / \mu \mathrm{M}$ & $\begin{array}{l}\text { plasma } \\
\mathrm{dpm} / \mathrm{ml}\end{array}$ \\
\hline \multirow[t]{4}{*}{ J.E. } & 5 & 693 & 90 & 3,760 & 338 & 152 & 34,950 & 5,310 \\
\hline & 15 & 776 & 90 & 2,930 & 264 & 152 & 11,290 & 1,710 \\
\hline & 60 & 93 & 90 & 820 & 74 & 152 & 2,510 & 380 \\
\hline & 78 & 31 & 90 & 800 & 70 & 152 & 1,730 & 260 \\
\hline \multirow[t]{3}{*}{ M.K. } & 10 & 437 & 147 & 2,500 & 367 & 178 & 21,850 & 3,890 \\
\hline & 21 & 287 & 145 & 1,990 & 289 & 159 & 12,960 & 2,060 \\
\hline & 53 & 154 & 178 & 1,110 & 197 & 177 & 4,180 & 740 \\
\hline \multirow[t]{4}{*}{ J.E.+glycine } & 6 & 718 & 165 & 2,490 & 413 & 811 & 10,940 & 8,870 \\
\hline & 18 & 938 & 145 & 2,640 & 378 & 826 & 4,550 & 3,760 \\
\hline & 39 & 357 & 188 & 1,780 & 333 & 937 & 1,700 & 1,590 \\
\hline & 61 & 359 & 151 & 1,500 & 227 & 821 & 1,200 & 990 \\
\hline \multirow[t]{4}{*}{ M.S. + glycine } & 6 & 2,570 & 114 & 7,030 & 798 & 1,014 & 9,310 & 9,440 \\
\hline & 16 & 1,116 & 114 & 3,800 & 434 & 936 & 4,910 & 4,590 \\
\hline & 29 & 773 & 114 & 3,010 & 424 & 859 & 3,210 & 2,760 \\
\hline & 59 & 658 & 121 & 2,360 & 286 & 774 & 1,880 & 1,450 \\
\hline \multirow[t]{8}{*}{ Patients } & 8 & 42 & 115 & 1,610 & 188 & 486 & 13,230 & 5,960 \\
\hline & 28 & 19 & 119 & 1,780 & 207 & 413 & 5,400 & 2,430 \\
\hline & 50 & 5 & 113 & 1,570 & 183 & 442 & 3,710 & 1,670 \\
\hline & 60 & 3 & 119 & 1,470 & 171 & 462 & 3,110 & 1,400 \\
\hline & 8 & 38 & 119 & 660 & 81 & 904 & 7,150 & 6,540 \\
\hline & 19 & 54 & 115 & 1,280 & 158 & 924 & 4,340 & 3,680 \\
\hline & 27 & 25 & 138 & 1,120 & 138 & 916 & 3,230 & 2,950 \\
\hline & 58 & 0 & 134 & 1,020 & 125 & 807 & 2,510 & 2,030 \\
\hline
\end{tabular}

\footnotetext{
${ }^{1}$ Formaldemethone derivative of the $\beta$ carbon of serine.
} 
InJ.E., the specific activities of serine differed little in the presence or absence of glycine infusion. However, the total dpm in serine per $\mathrm{ml}$ of plasma was higher; this was balanced by an increase in the concentration of serine in the plasma. These observations, together with the real dilution of the label in glycine, suggest that large amounts of glycine stimulate some aspect of the conversion of the second carbon of glycine to serine.

\section{Conversion of the $\alpha$ Carbon of Glycine to the $\beta$ Carbon of Serine}

Degradation of the serine isolated from plasma and precipitation of $\beta$ carbon as formaldemethone provided some clarification of these observations. The incorporation of the $\alpha$ carbon of glycine to the $\beta$ carbon of serine was higher in the two control subjects receiving large amounts of glycine by infusion than it was in the two control subjects studied without the glycine load.

Data for the patients and for controls given exogenous glycine are illustrated in figure 4 . Both groups had comparable concentrations of glycine and comparable dilutions of administered labeled glycine. Actually, all data for the controls, with or without glycine infusion, markedly exceeded those of the patients. The curves for the patients approximate the abscissa, indicating virtually no conversion. In fact, data obtained for the patients do not differ significantly from background counting.

There was no incorporation of glycine- $1{ }^{14} \mathrm{C}$ into $\beta$ carbon of serine in either patients or controls.

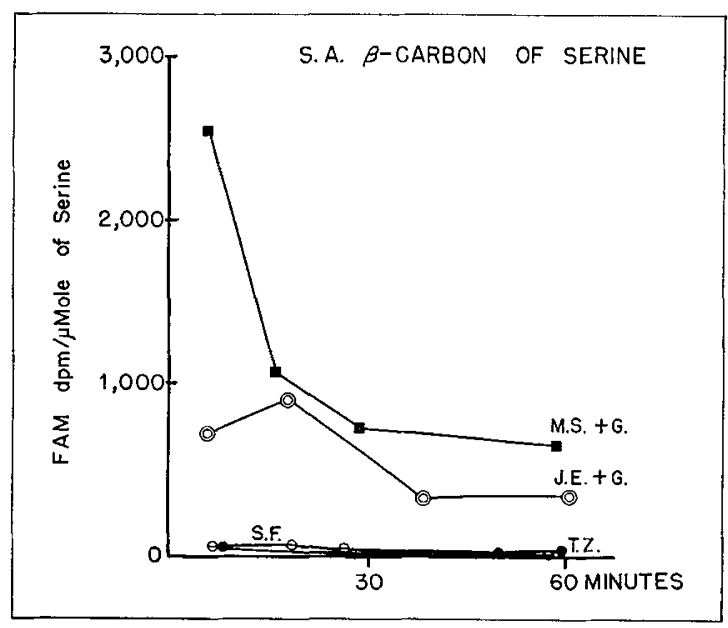

Fig.4. Conversion of glycine-2-14 $\mathrm{C}$ to the $\beta$ carbon of serine. The ratio of the radioactivity in formaldemethone $(\mathrm{dpm} / \mathrm{ml}$ of plasma) to serine $(\mu \mathrm{M} / \mathrm{ml}$ of plasma) expresses the specific activity of the $\beta$ carbon of serine.

\section{Discussion}

Evidence has been reported that interconversions of glycine and serine are abnormal in ketotic hyperglycinemia. The formation of serine from glycine-2- ${ }^{3} \mathrm{H}$ in a patient with ketotic hyperglycinemia was much slower than it was in control subjects [19]. The curve obtained appeared qualitatively different from those of the controls and quite similar to those obtained with glycine-2- ${ }^{14} \mathrm{C}$ in our patients with nonketotic hyperglycinemia. Similarly, in parents of a patient with ketotic hyperglycinemia, in comparison with data from normal subjects, the administration of glycine loads yielded higher concentrations of glycine and lower concentrations of serine [24]. However, in a patient with ketotic hyperglycinemia, the concentrations of glycine in the plasma increased to very high levels after the administration of serine loads [6], suggesting that the conversion of serine to glycine was rapid or even accelerated. Furthermore, in a heterozygous infant, the offspring of parents also having a ketotic hyperglycinemic baby, a serine load produced higher concentrations of glycine than it did in controls [1], even though glycine loading yielded lower concentrations of serine that it did in controls. These observations suggest that while glycine is inefficiently converted to serine, serine is converted to glycine at increased rates. The addition of serine to human liver homogenates increased the conversion of labeled glycine to serine [1], presumably by providing a source of the one carbon unit, hydroxymethyltetrahydrofolic acid. In the same heterozygous infant [1], this stimulation by serine was greater than that found in controls. These observations suggest that the enzyme serine hydroxymethyltransferase is intact, although there is defective conversion of glycine to serine.

Very few data are available on the metabolism of glycine in nonketotic hyperglycinemia. In one patient studied [9], oral loading with serine resulted in increases in plasma concentrations of glycine that were a little greater than those observed in controls. These data indicate that serine is readily converted to glycine, but do not deal with the conversion of glycine to serine.

The data obtained in this study indicate that in nonketotic hyperglycinemia, there is a defect in the oxidation of carbon 1 of glycine to $\mathrm{CO}_{2}$. In controls, glycine${ }^{1-14} \mathrm{C}$ was rapidly converted to ${ }^{14} \mathrm{CO}_{2}$. The formation of ${ }^{14} \mathrm{CO}_{2}$ from glycine-2-14 $\mathrm{C}$ was much slower, as one would expect if glycine were first converted to serine and then oxidized via the citric acid cycle in order to release the second carbon as $\mathrm{CO}_{2}$ (fig. 1). Formation of $\mathrm{CO}_{2}$ from glycine- $1{ }^{14} \mathrm{C}$ in the patients was qualitatively different from that of controls and resembled oxidation of glycine-2-14 C. A defect in the immediate oxidation of the first carbon of glycine would be consistent 
with a defect in glycine oxidase or in the enzyme responsible for the conversion of glycine to $\mathrm{CO}_{2}$ and hydroxymethyltetrahydrofolate.

The other major finding in these two patients with nonketotic hyperglycinemia was the virtual absence of the conversion of carbon 2 of glycine to carbon 3 of serine. This is consistent with the overall inefficiency of the conversion of glycine-2-14 $\mathrm{C}$ to serine. Glycine- $1-{ }^{14} \mathrm{C}$ conversion to serine was not different from that of controls with comparable pools of glycine. These observations could be explained by a defect in glycine oxidase, with defective conversion of glycine- $1-{ }^{14} \mathrm{C}$ to ${ }^{14} \mathrm{CO}_{2}$. Since the $\mathrm{Km}$ of glycine oxidase is very large, it is not thought to play a major role in glycine degradation. A defect in this enzyme, which deaminates glycine to form glyoxylate, could lead to diminished formation of carbon 3 of serine from glycine- $2-{ }^{14} \mathrm{C}$, if glyoxylate were the only pathway by which carbon 2 of glycine could be converted to carbon 3 of serine. This appears unlikely. This assumption is supported by preliminary data on the metabolism of $1-^{14} \mathrm{C}$-labeled glyoxylate to ${ }^{14} \mathrm{CO}_{2}$. The data would also be consistent with a defect in the succinyl CoA-glycine cycle, but under these circumstances, one would expect problems with heme synthesis. The data obtained provide evidence for a close association in man between the production of $\mathrm{CO}_{2}$ from carbon 1 of glycine and the formation of carbon 3 of serine from carbon 2 of glycine.

A close relation between the production of $\mathrm{CO}_{2}$ and $\mathrm{NH}_{3}$ from glycine and the synthesis of serine has been observed in vitro in avian liver by RICHERT et al. [21] and in bacteria by SAgers and Gunsalus [22]. The following series of reactions has been proposed [21, 22] in which $\mathrm{FH}_{4}$ is used to indicate tetrahydrofolic acid and $\mathrm{FH}_{4} \mathrm{CH}_{2} \mathrm{OH}$, its hydroxymethyl derivative:

$$
\begin{aligned}
\text { 1: } & \mathrm{NH}_{2} \mathrm{CH}_{2} \mathrm{COOH}+\mathrm{FH}_{4}+\mathrm{H}_{2} \mathrm{O} \rightarrow \mathrm{FH}_{4} \mathrm{CH}_{2} \mathrm{OH}+ \\
& \mathrm{CO}_{2}+\mathrm{NH}_{3} \\
\text { 2: } & \mathrm{FH}_{4} \mathrm{CH}_{2} \mathrm{OH}+\mathrm{NH}_{2} \mathrm{CH}_{2} \mathrm{COOH} \rightarrow \\
& \mathrm{HOCH}_{2} \mathrm{CHNH}_{2} \mathrm{COOH}+\mathrm{FH}_{4}
\end{aligned}
$$

The overall reaction for the synthesis of serine from glycine in this pathway would be as follows:

\section{3: $2 \mathrm{NH}_{2} \mathrm{CH}_{2} \mathrm{COOH}+\mathrm{H}_{2} \mathrm{O} \rightarrow \mathrm{HOCH}_{2} \mathrm{CHNH}_{2} \mathrm{COOH}$ $+\mathrm{CO}_{2}+\mathrm{NH}_{3}$}

There are many sources of $\mathrm{FH}_{4} \mathrm{CH}_{2} \mathrm{OH}$, other than glycine; they constitute the so-called one carbon pool. Reaction 1, therefore, is not required for the conversion of glycine to serine via reaction 2 , which is catalyzed by serine hydroxymethyltransferase, also known as serine aldolase and serine hydroxymethylase. Reaction $I$ is complex, requiring nicotinamide adenine dinucleotide (NAD) and pyridoxal phosphate as cofactors.
Reversal of the overall process listed in reaction 3 has been documented [11], but this $\mathrm{CO}_{2}$ fixation reaction does not necessarily proceed through reversal of reactions 1 and 2. The enzyme catalzying the decarboxylation of glycine in Peptococcus glycinophilus has been extensively purified by KLEIN and SAGERS [14] and found to be reversible. Glyoxylate and glycolate did not participate in these exchanges between the carboxyl group of glycine and $\mathrm{CO}_{2}$.

A defect in reaction 1 in nonketotic hyperglycinemia would explain the data obtained in these patients. Inability to form $\mathrm{CO}_{2}$ and $\mathrm{FH}_{4} \mathrm{CH}_{2} \mathrm{OH}$ from glycine would result in a defective formation of ${ }^{14} \mathrm{CO}_{2}$ from glycine- $1-{ }^{14} \mathrm{C}$ and of serine-3-14 $\mathrm{C}$ from glycine-2-14 $\mathrm{C}$, while serine- $1-{ }^{14} \mathrm{C}$ could readily be made from glycine${ }^{1-14} \mathrm{C}$ and a pool of $\mathrm{FH}_{4} \mathrm{CH}_{2} \mathrm{OH}$ from sources other than glycine.

The observations, in our control subjects, that glycine infusion increased rather than decreased the metabolism of glycine to $\mathrm{CO}_{2}$ and appeared also to increase the formation of the $\beta$ carbon of serine from glycine, suggest that large amounts of glycine may stimulate reaction 1. The data are consistent with the experiences of ARnstein and Neuberger [2] who found greater rates of conversion of glycine to serine in rats fed diets with a higher than usual content of glycine. The interpretation that the conversion of glycine to serine may operate physiologically only in the presence of large quantities of glycine is not consistent with observations in hyperglycinemia. Data in both man and rat suggest the hypothesis that formation of $\mathrm{CO}_{2}$ and $\mathrm{FH}_{4} \mathrm{CH}_{2} \mathrm{OH}$ from glycine is a physiologically important reaction which can be stimulated by large amounts of glycine. NEWMAN and MAGASANIK [18] have reported evidence that in $E$. coli, the enzyme system which converts glycine to single carbon units is adaptive. It is induced by glycine and repressed by single carbon units derived from other sources.

The mechanism of this reaction has been clarified in the $P$. glycinophilus system by KLEIN and SAGRRs [13, 14]. Four protein fractions $\left(P_{1}, P_{2}, P_{3}\right.$ and $\left.P_{4}\right)$ have been separated; all were required to catalyze the overall reaction of glycine and $\mathrm{FH}_{4}$ to yield $\mathrm{FH}_{4} \mathrm{CH}_{2} \mathrm{OH}$, $\mathrm{CO}_{2}$ and $\mathrm{NH}_{3}$. $\mathrm{P}_{1}$, which contains bound pyridoxal phosphate, and $\mathrm{P}_{2}$, a heat-stable protein, must be combined to yield $\mathrm{CO}_{2}$ from glycine. NAD and $\mathrm{FH}_{4}$ are not required for this decarboxylation. $\mathrm{P}_{3}$ is a flavoprotein which, when combined with $P_{2}$, is reduced by glycine and transfers electrons to NAD [3]. $\mathrm{P}_{\mathbf{4}}$ must be coupled to the other fractions to transfer the $\alpha$ carbon of glycine to $\mathrm{FH}_{4}$. It is not now known whether the system studied in avian liver [21] is the same one, or whether these mechanisms are operative in mammalian systems. It will be of considerable interest to explore them in hyperglycinemia. 


\section{Summary}

The metabolism of glycine was studied in two patients with nonketotic hyperglycinemia. The experiment was designed to assess the isotope content of respiratory $\mathrm{CO}_{2}$, glycine, serine and carbon 3 of serine after the separate intravenous injections of glycine- $1-{ }^{14} \mathrm{C}$ and glycine-2-14 $\mathrm{C}$. Conversion of the first carbon of glycine to $\mathrm{CO}_{2}$ was considerably slower in the patients than in the controls. In the patients, there was virtually no conversion of the second carbon of glycine to the third carbon of serine. These data indicate a defect in nonketotic hyperglycinemia in the reaction which forms $\mathrm{CO}_{2}$ and hydroxymethyltetrahydrofolic acid from glycine.

\section{References and Notes}

1. Ando, T.; Arakawa, T. and Tada, K.: Glycine serine interconversion in the heterozygotes of hyperglycinemia. The 4th Proceedings of Pediatric Research on Metabolism. Kyoto, 1966 (in press).

2. Arnstein, H.R.V. and Neuberger, A.: The synthesis of glycine and serine by the rat. Biochem.J. 55: 271 (1953).

3. BAginski, M.L. and Hunneckens, F. M.: Electron transport function of the heat-stable protein and a flavoprotein in the oxidative decarboxylation of glycine by Peptococcus glycinophilus. Biochem. biophys. Res. Commun. 23: 600 (1966).

4. BRAY, G.A.: A simple efficient liquid scintillator for counting aqueous solutions in a liquid scintillation counter. Anal. Biochem. 1: 279 (1960).

5. Ziter, F.A.; Heiner, D. C. ; Bray, P.F.; Madsen, J.A. and NyHAN, W.L.: The clinical findings in a patient with nonketotic hyperglycinemia. Pediat. Res. 2: 250 (1968).

6. Childs, B.; Nyhan, W. L.; Borden, M.; Bard, L. and Cooke, R. E. : Idiopathic hyperglycinemia and hyperglycinuria, a new disorder of amino acid metabolism. Pediatrics 27: 522 (1961).

7. FREDRICKSON, D.A. and Ono, K.: An improved technique for assay of $\mathrm{C}^{14} \mathrm{O}_{2}$ in expired air using the liquid scintillation counter. J.Lab.clin. Med. 51: 147 (1958).

8. Frisell, W.R.; MeEch, L.A. and MacKenzie, C. G.: A simplified photometric analysis for serine and formaldehyde. J. biol. Chem. 207: 709 (1954).

9. Gerritsen, T.; Kaveggia, W. and Waisman, H.A.: A new type of idiopathic hyperglycinemia with hypooxaluria. Pediatrics 36: 882 (1965).

10. Jefray, H. and Alvarez, J.: Liquid scintillation counting of carbon 14: Use of ethanolamine ethylene glycol monomethyl ether toluene. Anal. Chem. 33: 612 (1961).
11. Kawasaki, H.; Sato, T. and Kikuchi, G.: A new reaction for glycine biosynthesis. Biochem. biophys. Res. Commun. 23: 227 (1966).

12. KisLiuk, R.L.: Studies on the mechanism of formaldehyde incorporation into serine. J. biol. Chem. 227: 805 (1957).

13. KLEIN, S.M. and SAGERS, R.D.: Flavin-linked glycine dehydrogenase from Peptococcus glycinophilus. Bact. Proc. 103 (1966).

14. KLeIN, S. M. and SAgers, R.D.: Glycine metabolism. 1. Properties of the system catalyzing the exchange of bicarbonate with the carboxyl group of glycine in Peptococcus glycinophilus. J. biol. Chem. 241: 197 (1966).

15. MABry, C. C. and Karam, A.: Idiopathic hyperglycinemia and hyperglycinuria. Southern med.J. 56: 1444 (1963).

16. MacKenzie, C. G.: Formation of formaldehyde and formate in the biooxidation of the methyl group. J.biol. Chem. 186: 351 (1950).

17. Moore, S. and Stein, W.H.: A modified ninhydrin reagent for the photometric determination of amino acids and related compounds. J. biol. Chem. 211: 907 (1954).

18. Newman, E.B. and Magasanik, B.: The relation of serine-glycine metabolism to the formation of single-carbon units. Biochim. biophys. Acta 78: 437 (1963).

19. NyHAN, W.L. and Chrlds, B.: Hyperglycinemia. V.The miscible pool and turnover rate of glycine and the formation of serine. J. clin. Invest. 43: 2404 (1964).

20. Rampini, S.; Vischer, D.; Gurtius, H. G.; ANders, P.W.; Tancredi, F.; Frischknecht, W. und Prader, A.: Hereditäre Hyperglycinämie. Helv.paediat. Acta 22: 135 (1967).

21. Richert, D.A.; Amberg, R. and Wilson, M.: Metabolism of glycine by avian liver. J. biol. Chem. 237: 99 (1962).

22. SAgers, R.D. and Gunsalus, Y.C.: Intermediary metabolism of Diplococcus glycinophilus. 1. Glycine cleavage and one-carbon interconversions. J. Bact. 81: 541 (1961).

23. Stokke, O.; Eldjarn, L.; Norum, K.R.; SteenJohnsen, J. and Harvorsen, S.: Methylmalonic acidemia. A new inborn error of metabolism which may cause fatal acidosis in the neonatal period. Scand.J. clin. Lab. Invest. 20: 313 (1967).

24. TADA, K. and Ando, T.: Congenital hyperglycinemia. Demonstration of a minor defect in the parents. Tohoku J.exp. Med. 85: 105 (1965).

25. VAN Slyke, D.D. and Volch, J.: Manometric carbon determination. J.biol. Chem. 136: 509 (1940).

26. Zachmann, M.; Cleveland, W.W.; Sandberg, 
D.H. and Nyhan, W.L.: Concentrations of amino acids in plasma and muscle. Relationship to androgen metabolism during growth and development in the male. Amer. J. Dis. Child. 112: 283 (1966).

27. Pediatric Maintenance Solution (Baxter, $25 \mathrm{mEq} / 1$ $\mathrm{Na}, 10 \mathrm{mEq} / \mathrm{l} \mathrm{Cl}, 5 \mathrm{mEq} / \mathrm{l}$ lactate and $5 \%$ glucose) .

28. We are grateful to Doctors Samuel Giammona and Patricia Zelkowtrz for advice and assistance in developing the procedures for gas collection; to Mr. RICHARD WeHR for assistance with the Amino Acid Analzyers; and to Mr. Michael L. Rehberg.

29. This investigation was supported by USPHS Grants HD 02609-04 and HD 00341-07 from the National Institute of Ghild Health and Human
Development; Grant NB 05503 from the National Institute of Neurological Diseases and Blindness; Grant FR 00261 from the General Clinical Research Branch, NIH; and the Children's Bureau Grant 408.

30. The experimental undertakings in both control and patient subjects were conducted in accordance with institutional regulations regarding human experimentation. Informed consent was obtained from the appropriate guardians in all instances.

31. Requests for reprints should be addressed to: Wrlliam L. Nyhan, M.D., Department of Pediatrics, University of Miami School of Medicine, Miami, Fla. 33152 (USA). 